Proc. of the Third Intl. Conf. on Advances in Economics, Management and Social Study - EMS 2015

Copyright (C) Institute of Research Engineers and Doctors, USA .All rights reserved.

ISBN: 978-1-63248-058-3 doi: 10.15224/ 978-1-63248-058-3-54

\title{
Determinants of Knowledge-based Human Capital in ASEAN Five plus Three Countries
}

\author{
Wong Mei Foong
}

\begin{abstract}
Develop towards a knowledge-based economy is extremely important for the ASEAN five plus three countries, since the countries face challenges at the global fronts and technological changes; the rules of competition have changed. A country's competitive advantage is no longer dependent solely on factors such as labor, land and natural resources, but on its potential to produce, acquire, utilize and disseminate knowledge. Thus, this is essentially a shift from economic development based on resources to development based on knowledge where human capital (consequently education) emerges as crucial public policy themes for creating wealth and increasing the quality of life. This paper attempts to identify the determinants of knowledge-based human capital in ASEAN five plus three countries. The empirical findings of the human capital analyses indicate significant economic and demographic variables including the Gross Domestic Product (GDP) and fertility rate.
\end{abstract}

Keywords - Human capital, economic growth, fertility rate, mortality rate, interest rate, ASEAN five plus three countries.

\section{Introduction}

What are the factors that affect the schooling and human capital? Is downturn economy slow down human capital accumulation, especially among the poor, thus transmitting poverty across generations? Policymakers in the ASEAN five plus three countries, as well as such international organizations as the World Bank, often worry that household that are unable to smooth consumption during downturn economy may cut back on expenditures on the education. There is no formally acceptable model for knowledge-based human capital determinants although some researchers have tried to derive human capital equations from the Mincerian earning function. This particularly explains why previous studies on human capital determinants do not consistently use the same set of independent variables. (See Chu, et al. (2013).

According to Schady (2004), in general, a downturn of economy (measured by low GDP) will depress current employment and wage prospects, so the opportunity cost of attending school will fall. Holding everything else the same, this should lead to increased investment in human capital. But a downturn of economy could also make borrowing constraints more binding and thus reduce the total amount of schooling chosen. Thus the effect of downturn of economy on schooling is ambiguous in theory. People may choose more or less schooling, they may anticipate or postpone further schooling, and they may expend more or less effort in school.

Wong Mei Foong

Tunku Abdul Rahman University College

Malaysia
Generally, the decision to acquire skills via education involves the interaction of two important economic factors, both of which may exhibit significant variability over the business cycle: the expected rate of return on human capital investments; and the ability to finance schooling. The expected rate of return depends, among other things, on opportunity cost considerations (foregone income, Altonji and Siow, 1987); on direct educational costs (tuition, fees); and on expectations about future professional employment possibilities and future earnings. The ability to purchase education, on the other hand, is determined by the availability and cost of funds (in the form of family wealth, student - or other type of-loans, student aid, part-time job opportunities and so on). According to Hopkins (2004), with high level of interest rate, individuals are unwilling (or unable) to borrow in order to invest in education, thus the share of the population with higher education always falls. As has already been noticed by Galor and Zeira (1993), Atkinson (1975), if borrowing is difficult and costly, those who inherit a large initial wealth and do not need to borrow have better access to investment in human capital. It is supported by Dellas and Koubi (2003); they argued that schooling respond negatively to the expected real interest rate. Their results generally support the view that variation in opportunity costs associated with business cycles plays a major role in schooling decisions.

The debates about the relationship between population growth, human capital and economic growth have become a controversial issue in recent years. Rosenzweigh (1988) argued that larger families directly impede human capital formation and the inability of couples to control fertility is an important determinant of investment in human capital. It is supported by Temel's (2013) quantity-quality trade-off hypothesis, i.e., the smaller the family size, the higher the investment in human capital; high fertility impedes human capital formation. Thus, government should provide the means for fertility control and disseminate the information about drawback of high fertility. Tamura (2004) argued that fertility depends positively on the possibility of an early death, or a young adult decease. For the reason that human capital investments are made prior to the realization of survival from young adult to old adult, higher young adult mortality, by rising the number of children born, decreases human capital investment in each child. This is the standard Becker and Lewis (1973) relations of quality and quantity of children. If young adult mortality depends on the average human capital of young adults, then an endogenous demographic transition takes place. The economy progresses from high mortality, high fertility, slow human capital accumulation, and slow (if any) economic growth to low mortality, low fertility, rapid human capital accumulation and rapid economic growth. Human capital accumulation reduces young adult mortality, which consecutively bring on lower fertility. Lower fertility decreases the cost of human capital investment, and thus 
Proc. of the Third Intl. Conf. on Advances in Economics, Management and Social Study - EMS 2015

Copyright (C) Institute of Research Engineers and Doctors, USA .All rights reserved.

ISBN: 978-1-63248-058-3 doi: 10.15224/ 978-1-63248-058-3-54

parents increase their human capital investments per child. This leads to a virtuous cycle in which human capital growth leads to lower fertility and more rapid human capital growth. Of course there exists a limit to the cycle, since young adult mortality is bounded below by zero (See Chu, et al., 2013).

It is interesting and timely to determine whether factors such as economic growth, mortality, fertility and interest rates contributing to human capital, in particular in ASEAN five plus three countries. Therefore, this motivates me to study the determinants of human capital in ASEAN five plus three countries by using panel cointegration method. The panel cointegration method provides more powerful tests and estimates, and which has many advantages over the traditional panel models. Firstly, the cointegration tests are more powerful and allow us to increase the amount of information coming from the cross-sectional data. In other words, it can estimate the long-run equilibrium relationship that links the variables in the cointegration tests and estimates, which allows for heterogeneity among individual members of the panel, including heterogeneity in both the long-run cointegration vectors and the dynamics (Barnerjee, 1999; Perman and Stern, 2003; Pedroni, 2000, 2004; Breitung and Pesaran, 2008). Secondly, most previous studies that have used the traditional static panel model have been at a disadvantage in the sense that they cannot account for much of the dynamics regardless of whether they are time-averaged or not (Sarantis and Stewart, 2001).

The reminder of this paper is structured as follows. Section (II) describes the methodology and data set. Section (III) presents the empirical results and findings, including their policy implications. Finally, Section (IV) concludes the paper.

\section{Methodology}

The first step is to analyze the unit root properties of the data in order to determine the persistence of the human capital model. Panel unit root tests have been developed on the same principles that underlie the conventional Augmented DickeyFuller (ADF) test. Their most valuable feature is the degree of homogeneity that they allow. The panel unit root test proposed by Levin et al. (2002, hereafter LLC) allows for heterogeneity of the intercepts across members of the panel. Im et al. (2003, hereafter IPS) proposed the between-group panel unit root tests that allow for heterogeneity of the autoregressive root under the alternative. While Breitung (2000, hereafter UB) found that the loss of power was due to the bias correction terms in LLC (2002) and a detrending bias in IPS (2003). ${ }^{1}$ On the other hand, Maddala and Wu (1999) and Choi (2001) proposed the same kinds of panel unit root tests be performed using a Fisher statistic. However, the null of all unit root tests is having a unit root in a series, but there is a confusing

\footnotetext{
1 The differences between UB and LLC panel unit root tests are the autoregressive portion is removed when constructing the standardized proxies, and that the proxy is transformed and detrended.
}

alternative which is stationarity in LLC and Breitung (2000) tests, and there are also some cross sections without a unit root based on the IPS test, Fisher-ADF test and Fisher-Philips Perron (hereafter Fisher-PP) test. Therefore, the LLC and Breitung (2000) tests are conducted which assumed a common unit root process; while, the assumptions of individual unit root processes in the IPS (2003) test is match the Fisher-type tests which used the ADF and PP tests. In addition, Hadri (hom) and Hadri (het) represent the Hadri (2000) Kwiatkowski-Philips-Schmidt-Shin (KPSS) test which assumes homogeneity and heterogeneity, respectively, in the estimation of the long-run variance. The tests were calculated employing the Bartlett kernel. Besides, it is noteworthy that the LLC, UB, IPS, Fisher-ADF and Fisher-PP tests examine the null hypothesis of non-stationarity, while the Hadri tests the null hypothesis of stationarity. The Fisher tests were calculated using an asymptotic Chi-square distribution. While, all other tests assume asymptotic normality.

The next step is to test whether human capital and determinants of human capital are cointegrated. The heterogeneous panel cointegration test which permits for cross-section interdependence with different individual effects is specified as follows:

$H_{i t}=\alpha_{i}+\delta_{i} t+\gamma_{1 i} Y_{i t}+\gamma_{2 i} M R_{i t}+\gamma_{3 i} F R_{i t}+\gamma_{4 i} I N T_{i t}+\varepsilon_{i t}$

where $H$ is the logarithm of human capital, $Y$ is the logarithm of real per-capita income ${ }^{2}, M R$ is the logarithm of mortality rate, $F R$ is the logarithm of fertility rate, and INT is the logarithm of interest rate. $i=1, \ldots, N$ for each country in the panel and $t=1, \ldots, T$ refers the time period. The parameters $\alpha_{i}$ and $\delta_{i}$ allow for the possibility of state-specific fixed effects and deterministic trends, respectively. $\varepsilon_{i t}$ denotes the estimated residuals which represent deviations from the long-run relationship. To test the null hypothesis of no cointegration, $\rho_{i}$ $=1$, the unit root test of on the residuals of $\varepsilon_{i t}=\rho_{i} \varepsilon_{i t-1}+w_{i t}$ is performed.

In this study, two types of panel cointegration tests are conducted. The first test I apply is the residual-based panel cointegration test developed by Pedroni (1999, 2004). Pedroni suggested a number of tests for cointegration that permit for heterogeneous slope coefficients across cross-sections. In this study, four tests, namely Panel PP test, Panel ADF test, Group PP test, and Group ADF test are conducted. These statistics are based on averages of the individual autoregressive coefficients associated with the unit root tests of the residuals for each countries in the panel. The panel and group tests both are distributed asymptotically as standard normal. In the null hypothesis, the residuals are nonstationary; rejection of null hypothesis indicates that there is cointegrating relationship. The second panel cointegration test used in this study is the

${ }^{2}$ I use per capita numbers in this paper for two reasons (Lanne and Liski, 2004). First, per capita numbers are less sensitive to territorial changes. Second, per capita numbers provide the variables in the same units for large and small countries; they control the scale of the economy. 
Proc. of the Third Intl. Conf. on Advances in Economics, Management and Social Study - EMS 2015

Copyright (C) Institute of Research Engineers and Doctors, USA .All rights reserved.

ISBN: 978-1-63248-058-3 doi: 10.15224/ 978-1-63248-058-3-54

Johansen-Fisher panel cointegration test which developed by Maddala and Wu (1999). Maddala and Wu (1999) used Fisher's result to propose a technique for combining tests from individual cross-sections to obtain a test statistic for the full panel. Two types of Johansen tests have been developed, namely the fisher test from the trace test and the Fisher test from the maximum eigen-value test. Finally we use the panel fully modified least squares (FMOLS) for heterogeneous cointegrated panels to estimate the long-run cointegrating vector between the human capital and its determinants.

The analyses are based on yearly frequency data spanning from 1970 to 2013, the longest period available for five ASEAN plus three (APT) countries. ASEAN Plus Three (APT) is a forum that functions as a coordinator of cooperation between the Association of Southeast Asian Nations and the three East Asia nations of China, Japan, and South Korea. ASEAN was founded on 8 August 1967 with five members: Indonesia, Malaysia, the Philippines, Singapore, and Thailand. The education attainment data up to the 2010 are interpolated from five-year observations from Barro (2013). Particularly, three educational groups were considered: below upper secondary education; upper secondary education; and tertiary education. This construction takes account of the variations across countries in the typical duration of primary and secondary schools. I should stress, however, that the data do not take account of differences in the quality of schooling across countries or over time. The information on quality for the broad sample that I am using is limited. It is widely recognised that school attainment will be at best an imperfect proxy for the true stock of human capital. It is expected, however, that (since many of the relevant skills are acquired through formal schooling) the correlation between years of education and human capital will be sufficiently high for analyses that use the former as a proxy for the latter to yield some useful information. ${ }^{3}$ The data of income, mortality rate, fertility rate and interest rate are downloaded from the World Bank (available at http://data.worldbank.org). The major advantage of the World Bank data set is that the data are fully comparable across space and time.

\section{Results and Findings}

Table I reports the results of the panel unit root tests. At the 5 percent significant level, the seven types of statistics provide strong evidence in support of the five series (human capital, real income per capita, mortality rate, fertility rate and interest rate) having a unit root when the variables are taken in levels and any causal inference from the series in levels would therefore be invalid. However, when using the first differences, the null of unit roots is strongly rejected at the 5 percent significance level for all series.

\footnotetext{
${ }^{3}$ According to Angel (2003), schooling may act as proxy for R \& D investment, which is highly skill intensive. While this is not exactly the idea behind the rate effects, a positive coefficient arising through this mechanism would also be consistent with the view that human capital contributes to the creation of useful knowledge.
}

TABLE I. Results for panel unit root tests

\begin{tabular}{lccccc}
\hline & $\begin{array}{c}\text { Human } \\
\text { Capital }\end{array}$ & Income & $\begin{array}{c}\text { Mortality } \\
\text { Rate }\end{array}$ & $\begin{array}{c}\text { Fertility } \\
\text { Rate }\end{array}$ & $\begin{array}{c}\text { Interest } \\
\text { Rate }\end{array}$ \\
\hline Levels & & & & & \\
LLC & -0.55 & 1.21 & 0.14 & 0.43 & -1.47 \\
UB & -0.41 & 0.79 & -0.85 & -0.68 & -0.40 \\
IPS & 1.55 & 2.33 & 1.19 & 1.06 & -0.54 \\
Fisher-ADF & 7.15 & 6.77 & 11.49 & 13.89 & 16.40 \\
Fisher-PP & 13.99 & 6.09 & 39.92 & 8.57 & 11.30 \\
Hadri (hom) & $8.94^{*}$ & $7.93^{*}$ & $7.64^{*}$ & $5.99^{*}$ & $7.38^{*}$ \\
Hadri (het) & $6.90^{*}$ & $7.76^{*}$ & $6.32^{*}$ & $5.71^{*}$ & $6.59^{*}$ \\
& & & & & \\
First difference & & & & & \\
LLC & $-29.18^{*}$ & $-3.48^{*}$ & $-3.43^{*}$ & $-11.56^{*}$ & $-14.47^{*}$ \\
UB & $-5.69^{*}$ & $-4.35^{*}$ & $-3.11^{*}$ & $-4.10^{*}$ & $-10.21^{*}$ \\
IPS & $-28.80^{*}$ & $-3.71^{*}$ & $-6.72^{*}$ & $-12.93^{*}$ & $-11.41^{*}$ \\
Fisher-ADF & $892.52^{*}$ & $39.19^{*}$ & $79.32^{*}$ & $173.98^{*}$ & $132.65^{*}$ \\
Fisher-PP & $1305.9^{*}$ & $128.19^{*}$ & $603.37^{*}$ & $368.42^{*}$ & $408.63^{*}$ \\
Hadri (hom) & -0.97 & 1.17 & 0.92 & 1.04 & -0.54 \\
Hadri (het) & -0.64 & 0.83 & 1.15 & 1.28 & -0.58 \\
\hline
\end{tabular}

Notes: LLC, UB and IPS are the panel unit root tests of Levin et al. (2002), Breitung (2000), Im et al. (2003), respectively. Fisher-ADF and Fisher-PP are the Maddala and Wu (1999) Fisher-ADF and Fisher-PP panel unit root test, respectively. Hadri (hom) and Hadri (het) represent the Hadri (2000) KPSS test which assumes homogeneity and heterogeneity, respectively. * indicates significance at the 5 percent level. Fisher tests are computed using an asymptotic Chi-square distribution. All other tests assume asymptotic normality

Therefore, it is concluded that all the series are non-stationary and integrated of order one, I(1). By using these results, I proceed to test for cointegration to determine if there is a longrun equilibrium relationship among these five variables to control for in the econometric specifications.

The results for both Pedroni residual-based panel cointegration tests and Johansen-Fisher panel cointegration tests are presented in Table II. As can be seen, all tests suggest that human capital, real income per capita, mortality rate, fertility rate and interest rate are cointegrated. The ADF and the PP statistics reject the null hypothesis of no cointegration at least at the 5 percent level, indicating that there exists a long-run relationship between human capital, real income per capita, mortality rate, fertility rate and interest rate. The panel Johansen-Fisher statistics from trace test and maximum eigenvalue test clearly support the presence of one cointegrating vector. The next step consists of the long-run equations which are estimated employing the FMOLS estimation technique for heterogeneous cointegrated panels.

When human capital variable is regarded as a dependent variable, the results of using the FMOLS estimation for heterogeneous cointegrated panel are presented in Table III. Table III reposts estimates of the long-run elasticities of human capital with respect to real income per capita, mortality

TABLE II. Results for panel cointegration tests

\begin{tabular}{|c|c|}
\hline Techniques & Test Statistics \\
\hline \multicolumn{2}{|l|}{ (a) Pedroni tests } \\
\hline Panel PP test & $-3.12 *$ \\
\hline Panel ADF test & $-2.67 *$ \\
\hline Group PP test & $-3.92 *$ \\
\hline Group ADF test & $-2.99 *$ \\
\hline \multicolumn{2}{|l|}{ (b) Johansen-Fisher tests } \\
\hline Fisher statistic from trace test & $73.39 *$ \\
\hline Fisher statistic from maximum eigen-value test & $41.50^{*}$ \\
\hline
\end{tabular}


rate, fertility rate and interest rate. The elasticities of human capital are crucial for understanding past and assessing future economic dynamics and representing the weights with which marginal relative changes of the economic and social factors contribute to the relative change of human capital. From the estimated equations, the human capital elasticity with respect to real income per capita is significant and positive. The panel FMOLS estimates for income elasticity is 0.09 (with t-statistic equal to 2.53), implying that a 1 percent increase in the real income per capita, the human capital on the average increases by about 0.09 percent. It is due to economic growth allows further development of education systems by providing higher levels of resources for educational expansion. This hypothesis is supported by the study of Cheng and Hsu (1997) in Japan but is in sharp contrast with that of Schady (2004) which show that a downturn of economy (measured by low GDP) will depress current employment and wage prospects, so the opportunity cost of attending school will fall. Holding everything else the same, this should lead to increased investment in human capital. Anyhow, Schultz (1988) found the income elasticity of public expenditures on primary and secondary education has been estimated to be around 1.5, suggesting that when incomes double, spending on education will rise by 150 percent.

The human capital elasticity with respect to mortality rate is negative and significant. Similarly, the human capital elasticity with respect to fertility rate is also negative and significant. It is consistent with the arguments of Tamura (2004) that high mortality and fertility slow down human capital accumulation thus slow down economic growth, vice versa. Low mortality and fertility lead to higher human capital accumulation and thus higher economic growth. Accordingly, women's education can start a virtuous cycle of education and economic improvement. In this virtuous cycle, an increase in women's education has the beneficial external effect of decreasing fertility and infant mortality and of increasing the "quality" of surviving children who are better educated and healthier. Furthermore, some of the studies argued that the rapid increase in population (resulted from high fertility) has resulted in a substantial increase in the number of school-age children. This has increase the burden for the carrying capacity of school systems and has resulted in split shifts, a reduction in the per capita expenditures per student, larger classes, and shared text materials in some cases. Among others, OECD (2003) supported that increasing demand for public educational services has deteriorate the quality of public schooling in many countries in the past few decades. Thus, some policy-makers favor privately run schools system because it is more responsive to shifts in demand and other economic forces than a public education system. But the risk

TABLE III. Results for panel FMOLS long-run estimates Dependent variable: Human capital

\begin{tabular}{lcccc}
\hline Country groupings & Income & $\begin{array}{c}\text { Mortality } \\
\text { Rate }\end{array}$ & $\begin{array}{c}\text { Fertility } \\
\text { Rate }\end{array}$ & $\begin{array}{c}\text { Interest } \\
\text { Rate }\end{array}$ \\
\hline Panel Group & $0.09 *$ & $-0.10^{*}$ & $-0.15^{*}$ & $0.06^{*}$ \\
& {$[2.53]$} & {$[-4.76]$} & {$[-4.95]$} & {$[5.24]$} \\
\hline \multicolumn{2}{l}{ Notes: * significant coefficient with 5 percent significance level. The values in [ ] denote the t-statistic. }
\end{tabular}

is that the rich go to the better private schools and the poor have to be contented with an inferior public school system. Consequently, employers in such developing countries tend to favor graduates of private schools over their public school counterparts.

The elasticity with respect to interest rate is positive and significant, implying that a 1 percent increase in the interest rate, the human capital (average years of schooling) on the average increases by about 0.06 percent. In other words, schooling decisions are positively related to changes in the interest rate. According to Dellas and Koubi (2003), whether one wants to emphasize a high interest rate as representing a high cost of financing education or a high opportunity cost of not transferring resources intertemporally by working (rather than investing in human capital), the result is that an increase in the interest rate is associated with a sizeable reduction in enrollment rates for almost all age groups considered. However, the positive interest rate elasticity from for the panel group suggest imperfections in access to capital for potential students, I could not find support for the alternative view those students relied on subsidization by family.

\section{Conclusion}

In this paper I identify the determinants of the knowledgebased human capital and investigate the cointegration relationship between human capital and its determinants in ASEAN five plus three countries over the period 1970-2013. Using recently developed panel methods to test for unit roots and cointegration, I conclude that there is strong evidence in favour of a long-run relationship between human capital and its determinants for all ASEAN five plus three countries.

The estimated fertility elasticity is negative and significant for ASEAN five plus three countries. This is due to the several reasons. In developing countries, large families tend to group among the poor. This perpetuates poverty and exacerbates inequality. Thus, large family size reduces the educational opportunities for the children of such families and also reduces the rate of savings by raising the dependency rate. Furthermore, high fertility harms the health of both mother and children. While this may be recognized by the family and accounted for in decision-making, this is unlikely in families where women are disempowered and/or the literacy rate is low. Family members in large families are likely to go hungry more than small families.

Furthermore, a rapidly growing population is normally characterized by a high proportion of persons less than 15 years. This youth effect, as it is normally called, creates a large supply of people too young to work and does not assist in the growth of output. This situation is typical of developing countries such as Philippines, Malaysia and Indonesia. On the other hand, rapid population growth affects the percentage available to be employed through the female availability effect. With a faster growth rate and more children to care for, fewer women are available to join the labor force. Both the dominant of the youth effect and the female availability effect 
suggest that rapid population growth reduces the percentage of the population in the labor force which, in turn, has a depressing effect on economic growth per capita. These results are consistent with the argument of Dowling and Valenzuela (2004). Obviously, the public policy to control population growth and to plan for the changes in population structure is still evolving. From a public policy point of view, it is crucial to emphasize both of these issues since they will have an increasingly crucial role to play in the future of the ASEAN five plus three countries. In particular, the richer economies that underwent the demographic transition early begin to age in the next few decades and the middle-income countries experience an increase in the dependency ratio, requiring a shift in budget allocations toward the care of these ageing groups.

\section{References}

[1] A. Banerjee, "Panel data unit roots and cointegration: an overview," Oxford Bulletin of Economics and Statistics, vol. 61, pp. 607-629, 1999.

[2] A. B. Atkinson, "The Economics of Inequality," Oxford: Clarendon Press, 1975.

[3] A. Chu, G. Cozzi, and C. Liao, "Endogenous fertility and human capital in a Schumpeterian growth model," Journal of Population Economics, vol. 26, pp. 181-202, 2013.

[4] A. Levin, C. F. Lin, and C. Chu, "Unit root tests in panel data: asymptotic and finite-sample properties," Journal of Econometrics, vol. 108, pp. 1-24, 2002

[5] B. S. Cheng, and R. C. Hsu. "Human capital and economic growth in Japan: an application of time series analysis," Applied Economics Letters , vol. 4, pp. 393-395, 1997.

[6] D. L. F. Angel, "Human capital in a global and knowledge-based economy," unpublished, 2003.

[7] G. S. Becker, and H. G. Lewis, "On the interaction between the quantity and quality of children," Journal of Political Economy, vol. 81, pp. S279-S288, 1973.

[8] G. S. Maddala, and S. Wu, "A comparative study of unit root tests with panel data and a new simple test," Oxford Bulletin of Economics and Statistics, Special issue, pp. 631-652, 1999.

[9] H, Dellas, and V. Koubi, "Business cycles and schooling," European Journal of Political Economy, vol. 19, pp. 843-859, 2003.

[10] I. Choi, "Unit root tests for panel data," Journal of International Money and Finance, vol. 20, pp. 249-272, 2001.

[11] J. Breitung, "The local power of some unit root tests for panel data," Advances in Econometrics, vol. 15, pp. 161-177, 2000.

[12] J. Breitung, and M. Pesaran, "Unit roots and cointegration in panels," in The econometrics of panel data: fundamentals and recent developments in theory and practice, L. Matyas and P. Sevestre, Eds. Kluwer Academic Publishers, 2008, pp. 279-322.

[13] J. G. Altonji, and A. Siow, "Testing the response of consumption to income changes with (noisy) panel data," The Quarterly Journal of Economics, vol. 102, pp. 293-328, 1987.

[14] J. M. Dowling, and M.R.Valenzuela, "Economic development in ASIA," Thomson Learning, 2004.

[15] K. Hadri, "Testing for stationarity in heterogeneous panel application," Econometric Journal, vol. 3, pp. 148-161, 2000.

[16] K. S. Im, M. H. Pesaran, and Y. Shin, "Testing for unit roots in heterogeneous panels," Journal of Econometrics, vol. 115, pp. 53-74, 2003.

[17] M. Hopkins, "Inequality of opportunity? Cross country evidence on the determinants of educational investment and returns," Unpublished, 2004.

[18] M. Lanne and M. Liski, "Trends and breaks in per-capita carbon dioxide emissions, 1870-2028," The Energy Journal, vol. 25, pp. 41 - 65, 2004.
[19] M. R. Rosenzweig, "Human capital, population growth, and economic development: Beyond correlations," Journal of Policy Modeling, vol. 10, pp. 83-111, 1988.

[20] N. R. Schady, "Do macroeconomic crises always slow human capital accumulation?" The World Bank Economic Review, vol. 18, pp. 131154, 2004.

[21] N. Sarantis, and C. Stewart, "Saving behavior in OECD countries: evidence from panel cointegration tests," Manchester School, vol. 69, pp. 22-41, 2001.

[22] Organisation for Economic Co-operation and Development, "Education at a Glance 2003," Paris: OECD, 2003.

[23] O. Galor, and J. Zeira, "Income distribution and macroeconomics," The Review of Economic Studies, vol. 60, pp. 35-52, 1993.

[24] P. Pedroni, "Critical values for cointegration tests in heterogeneous panels with multiple regressors," Oxford Bulletin of Economic and Statistics, vol. 61, pp. 653-678, 1999.

[25] P. Pedroni, "Panel cointegration: asymptotic and finite sample properties of pooled time series tests with an application to the PPP hypothesis," Econometric Theory, vol. 20, pp. 597-625, 2004.

[26] R. J. Barro, "A new data set of educational attainment in the world, 1950-2010," Journal of Development Economics, vol. 104, pp. 184-198, 2013

[27] R. Perman, and D. I. Stern, "Evidence from panel unit root and cointegration tests that the environmental Kuznets curve does not exist," The Australian Journal of Agricultural and Resource Economics, vol. 47, pp. 325-347, 2003.

[28] R. Tamura, "Human capital and economic development," Federal Reserve Bank of Atlanta: Working Paper Series 2004-34, 2004.

[29] T. Temel,. "Intensive margin and extensive margin adjustments of labor market: Turkey versus United States," Economics Bulletin, vol. 33, pp. 2307-2319, 2013.

[30] T. W. Schultz, "Education investment and returns," in Handbook of Development Economics, vol. 1, H. B. Chenery and T. N. Srinivasan, Eds. Amsterdam: Elsevier Science Publication, 1988.

\section{About Author (s):}

Wong Mei Foong is a Senior Lecturer of Finance at the Tunku Abdul Rahman University College. She currently lectures on courses in the areas of banking, investment and finance. She has published several articles in academic journals. She received her $\mathrm{PhD}$ in Development Economics and Master of Science in Financial Economics from the University of Putra Malaysia. 